\section{DE PASIONES IMAGINARIAS: LA NARRATIVA DE GERTRUDIS GÓMEZ DE AVELLANEDA}

\author{
Teodosio Fernández \\ Universidad Autónoma de Madrid \\ teodosio.fernandez@uam.es
}

\section{IMAGINARY PASSIONS: GERTRUDIS GÓMEZ DE AVELLANEDA'S NARRATIVE}

Cómo citar este artículo/Citation: Fernández, T. (2014). "De pasiones imaginarias: la narrativa de Gertrudis Gómez de Avellaneda". Arbor, 190 (770): a185. doi: http://dx.doi. org/10.3989/arbor.2014.770n6006
Copyright: (c) 2014 CSIC. Este es un artículo de acceso abierto distribuido bajo los términos de la licencia Creative Commons Attribution-Non Commercial (by-nc) Spain 3.0.
RESUMEN: El carácter confesional y la condición femenina y feminista de la obra de Gertrudis Gómez de Avellaneda han reclamado insistentemente el interés de la crítica. En contraste, este artículo presta atención a las novelas y leyendas de la escritora hispano-cubana en los aspectos que revelan una inspiración en buena medida libresca y ponen de manifiesto la consciencia y los notables recursos de la autora al transformar motivos y temas de origen muy variado en ficciones propias, conjugando experiencias personales, lecturas y observación de su entorno en un proceso creativo que siempre dejó constancia de su pertenencia al ámbito autónomo de la imaginación literaria.

PALABRAS CLAVE: Gertrudis Gómez de Avellaneda; novelas; leyendas; romanticismo; sentimiento; realidad; ficción.
ABSTRACT: Critics have recurrently pointed out the importance of confessional aspects and the feminine and feminist nature of Gertrudis Gómez de Avellaneda's work. However in this paper the attention will be focused in aspects that reveal a sort of bookish inspiration among her novels and tales. These aspects highlight the consciousness and notable skills of this Hispano-Cuban writer who was able to turn motifs and themes from different sources into fictions that are very much her own. Such fictions blend personal experiences, readings and an observation of her surroundings into a creative processes that, without doubt, left proof of her belonging to the autonomous field of literary imagination.

KEYWORDS: Gertrudis Gómez de Avellaneda; novels; legends; Romanticism; feeling; reality; fiction. 
La narrativa de Gertrudis Gómez de Avellaneda fue durante mucho tiempo la parte menos apreciada de su producción literaria, y la que menos atrajo el interés de la crítica. Fue también, probablemente, donde de forma más rotunda se plasmó desde el principio el romanticismo de la autora, fruto de la lectura entusiasta de novelistas en boga. Sobre sus preferencias al respecto hay un significativo fragmento en su correspondencia, en el cual, entre las razones que a fines de 1839 invocaba para que el reticente Ignacio Cepeda la visitara en Sevilla - por entonces amaba con pasión al escritor y abogado andaluz-, aducía las siguientes:

En primer lugar, porque quiero que conozcas al primer prosista de Europa, al novelista más distinguido de la época, tengo en lista El pirata, Los privados rivales, El Wawerley y El anticuario, obras del célebre Walter Scott.

Seguidamente Corina o Italia por Madame Staël. Novela descriptiva del más hermoso y poético país del mundo, y hecha esa descripción con la pluma de una escritora cuyo mérito conoces. Además, han dado muchos amigos en decirme que hay semejanzas entre mí y la protagonista de esa novela, y deseo por eso volver a leerla contigo y buscar la semejanza que se me atribuye con ese bello ideal de un genio como el de la Staël.

Sigue la Atala del inmortal y divino Chateaubriand, porque te agradan todas las escenas de la naturaleza, todos los corazones primitivos, en fin, el hombre en su estado normal; y esta linda obra te satisfará. Luego las poesías de Lista, Quintana y Heredia, porque como dice uno de estos poetas:

\author{
Verás la poesía \\ Del corazón y mente descendiendo, \\ El corazón y mente arrebatarse
}

(Gómez de Avellaneda, 1914, p. 116).

Su amante debería elegir una de las obras citadas para compartir su lectura. Cabe suponer que Cepeda, ante tal programa y dado su carácter frío aunque cortés, no acudió a la cita. Pero esa carta invita a comprobar que si los versos de Tula se insertaban sin problemas en la tradición hispánica reciente, era su entusiasmo por Walter Scott, Madame Staël o el vizconde de Chateaubriand lo que había de determinar en gran medida la orientación de su narrativa. A los autores mencionados cabe añadir otros, como el Bernardin de Saint-Pierre de Pablo y Virginia y, desde luego, Jean-Jacques Rousseau, por cuya lectura se la acusara de atea en La Coruña, según habría de recor- dar en su autobiografía (Gómez de Avellaneda, 1914, p. 72). De esa carta se deduce también la propensión de la escritora cubana a identificarse con las heroínas de los relatos que leía, inclinación que la llevaría a proyectarse en las protagonistas de sus ficciones y a elaborar sus personajes a partir de los caracteres observados en personas de su entorno. Esa conjunción de lecturas, inquietudes personales y observación fue la que sus lectores pronto encontrarían en $S a b$, su primera novela, en la que pudo expresar su nostalgia de la tierra natal que había dejado en 1836, idealizada por la distancia y los modelos literarios, y también sus anhelos de libertad y sus inquietudes sentimentales del momento. Se arrepentiría pronto: en las "dos palabras al lector" que servían de introducción a la novela manifestaba ya su desacuerdo con algunas de las ideas expresadas en el relato, redactado tres años antes, y decía esperar comprensión para los errores incluidos en sus páginas, "dictadas por los sentimientos, algunas veces exagerados pero siempre generosos de la primera juventud" (Gómez de Avellaneda, 1841, p. 6).

No precisó de qué errores se trataba, pero quizá fueran los mismos que determinaron la exclusión de esa novela cuando entre 1869 y 1871 se editaron en Madrid sus Obras literarias, compartidos en formas diversas por las otras obras que sufrieron la misma suerte: Dos mujeres, novela publicada en 1842-1843, y Guatimozín, último emperador de México, que El Heraldo de Madrid dio a conocer entre el 21 de febrero y el 25 de abril de $1846^{1}$.

Aunque difícilmente se puede encontrar en sus páginas una condena de la conquista de América más radical que la ofrecida por los propios cronistas de Indias cuando relataban episodios de crueldad excesiva e injustificada, en Guatimozín, último emperador de México - probablemente la novela de mayor interés entre las que durante el siglo XIX recrearon aquellos hechos, tanto en España como en Hispanoamérica - no faltaban ingredientes capaces de herir la susceptibilidad española: el talento militar, el valor y la tenacidad de Hernán Cortés no impedían advertir su deficiente condición moral, subrayada por contraste con la de sus rivales indígenas, magnánimos, caballerosos, cumplidores de la palabra empeñada, y además signados por un destino romántico tan infausto como atractivo. Como en el caso de $S a b$, no parece descaminado acudir a razones "políticas" para explicar su ausencia en las Obras literarias mencionadas², pero no son esas las cuestiones que estas páginas pretenden abordar. 
Tales razones, por otra parte, no justifican que se exagere el alcance "revolucionario" de esas obras llevándolo más lejos de lo que los propios textos permiten comprobar, como ha ocurrido sobre todo con Sab, quizá porque ha recibido una atención más insistente de la crítica. Sin duda la autora se pronunciaba contra las graves injusticias derivadas de los prejuicios o convenciones vigentes en torno a las razas, pero el desarrollo de los acontecimientos hacía que el problema de la esclavitud se difuminase a medida que la trama iba adquiriendo su configuración definitiva. Quedaban en el olvido los propósitos nunca cumplidos de conceder la libertad a sus esclavos que manifestara alguna vez Carlota, su joven y bella protagonista, y los indicios de protesta social, manifiestos desde que en las primeras páginas se lamentaran las terribles condiciones de vida que sufrían quienes llevaban en su frente la marca de la servidumbre, terminaban por diluirse cuando Sab, el más consciente de la injusticia, renunciaba a canalizar el odio de las víctimas contra sus victimarios para asumir hasta el final su condición de mulato y esclavo, como si solo la desgracia pudiera conformar su esencia y su existencia. "Superior a mi clase por mi naturaleza, inferior a las otras por mi destino, estoy solo en el mundo" (Gómez de Avellaneda, 1841, pp. 40-41), se lamentaba, como si el lector no supiera que renunciaba tanto a su libertad como a su fortuna por amor a Carlota: un amor desgraciado, al gusto de la literatura de la época y acorde con el temperamento y por entonces tal vez con las vivencias personales de la autora. Si alguna vez pensó en rebelarse contra los blancos opresores, Sab lo hizo a impulsos de esa misma pasión irresistible que después le exigía cuantos sacrificios contribuyeran a la felicidad de su dama - hasta salvar la vida repetidamente a Enrique Otway, el rival favorecido- a la vez que los celos debilitaban su razón y su cuerpo, hasta expirar como un mártir del amor en el mismo momento en que Carlota contraía matrimonio con el hombre al que ella amaba también apasionadamente.

La condición étnica y social resultaba ser de ese modo apenas un ingrediente más de la fatalidad romántica que impedía el final feliz. En cuanto se deja de insistir en su condición abolicionista, Sab revela otras facetas y plantea otros conflictos que enriquecen sus significados. Desde luego, su protagonista era similar a otros imaginados por escritores asociados a los gustos propios del romanticismo: enamorado de la hija de su amo - con la que había crecido en una poco original intimidad de hermanos, potenciada por la sangre en alguna proporción compartida-, amaba la libertad, pero prefería la esclavitud por amor, pues solo la nobleza y el dolor de una gran pasión parecían capaces de redimirlo de su miseria. Su superioridad quedaba ligada a la sublimidad y la sublimación de sus sentimientos - odio, ira, compasión y, sobre todo, amor-, y se realzaba en contraste con la miserable condición moral de su rival blanco, frío y calculador, hijo de alguien que representaba con eficacia el espíritu mercantil y especulador que parecía imponerse. La valoración positiva o negativa de los demás personajes relevantes era también proporcional a la intensidad de sus sentimientos y a la capacidad para el sacrificio, lo que permitía constatar la existencia de espíritus superiores como Sab y Carlota, y también en buena medida Teresa, esa prima de la protagonista que se descubría propicia a la pasión y a la renuncia. Tales espíritus superiores estaban siempre expuestos al desencanto ante la mediocridad de su entorno: Sab podía adivinar el triste destino de la enamorada Carlota, condenada a sufrir con el tiempo las consecuencias de ser "una pobre alma poética arrojada entre mil existencias positivas" (Gómez de Avellaneda, 1841, p. 117). Perdida entre los intereses mercantiles dominantes en su nueva familia y sobre todo ante la mezquindad y la avaricia que se vería obligada a reconocer en su marido, su felicidad habría de desvanecerse progresivamente, y de poco iba a servirle saber que Sab la había amado como ella necesitaba.

Tula llevaba así a su primera novela un proceso no previsto en los relatos más característicamente "románticos": la historia se prolongaba más allá de lo esperable, de modo que la "realidad" terminaba por poner fin a la "ilusión", conflicto que, elaborado a base de referencias literarias, suponía insertar dentro del relato una reflexión e incluso una valoración de la propia literatura. No es difícil comprobarlo: quizá Carlota soñó alguna vez ser Atala, o cuando menos, como Sab comprobó en algún momento, comprendía "la vida y felicidad de los salvajes", lo que le permitía imaginar que antes de los horrores de la conquista de América en Cuba "vivían felices aquellos hijos de la naturaleza", sobre un suelo virgen que "no necesitaba ser regado con el sudor de los esclavos para producirles: ofrecíales por todas partes sombras y frutos, aguas y flores, y sus entrañas no habían sido despedazadas para arrancarle con mano avara sus escondidos tesoros" (Gómez de Avellaneda, 1841, pp. 137138). La exaltación del hombre "natural", derivada de la lectura de Rousseau, animaba a asociar el pasado prehispánico con una mítica edad de oro que hacía de la conquista y de la desaparición de los antiguos habitantes de las Antillas nuevas manifestaciones de ese destino adverso que determinaba el desarrollo 
de los acontecimientos relatados. En la deriva de esos acontecimientos resultaba evidente la oposición de los valores espirituales y los sentimientos exaltados de los espíritus superiores con la mediocridad de los personajes que se mantenían apegados a la realidad ajustándose al espíritu positivista que terminaba imponiéndose. Ese conflicto, que dejaba en segundo término el problema de la esclavitud, abría un abismo entre las expectativas de los primeros y la incapacidad de los segundos para colmarlas, y era en la elaboración imaginaria de aquellos donde las lecturas de la autora resultaban absolutamente determinantes.

Por si en Sab esa relación no quedaba clara, Dos mujeres permitió a Gómez de Avellaneda ir más lejos y matizarla con notable precisión. Ambientada en Sevilla y Madrid a principios de 1817, esa novela contraponía las conductas de dos personajes femeninos que giraban en torno a un único varón: la esposa abnegada y dispuesta al sacrificio, y la amante que todo lo subordinaba a su pasión. La mera inclusión del adulterio pudo resultar escandalosa para un importante sector de los lectores, y quizá Tula se atuvo a la opinión de quienes desaconsejaban la reimpresión de la obra (Castillo de González, 1887, p. 69). Además, si Sab manifestaba ya un recelo evidente hacia el matrimonio - sus cadenas condenarían inexorablemente al tedio, al desengaño y al arrepentimiento-, esas reticencias parecían ahora confirmadas por una narradora que jamás había presenciado esa ceremonia "solemne y patética" del culto católico "sin un enternecimiento profundo mezclado de terror" (Gómez de Avellaneda, 1842-1843, I, p. 98). Tula volvía a prolongar una historia de amor más allá de la boda, y esta vez la infidelidad del marido daba al proceso un singular dramatismo, sobre todo si los hechos narrados se interpretan como presentación literaria de costumbres contemporáneas. En efecto, aunque conviene no olvidar que al publicar Dos mujeres la autora (razonablemente) aseguraba limitarse "a bosquejar caracteres verosímiles y pasiones naturales", y escribir "por mero pasatiempo", ajena a toda pretensión de exponer doctrinas morales o sociales (Gómez de Avellaneda, 1842-1843, I, pp. 6-7), eso no impide extraer de la novela las conclusiones preferidas por cada lector, y la condición "peregrina" que ella misma adjudicaba a su personalidad invita a ver en Gómez de Avellaneda a una defensora de la ruptura matrimonial (o divorcio). Pero la decepción y el suicidio de la condesa Catalina en Dos mujeres no pueden interpretarse solo como una crítica de las convenciones sociales que impedían su felicidad. Catalina era infeliz ya antes de que Carlos entrase en su vida, y la relación torturada que ambos establecieron nunca permitió esperar una solución positiva. En el momento decisivo era él quien sentía que lo que era "un sacrificio doloroso", el que afectaría a su esposa si él huía con su amante, se transformaba en "una felicidad destruida", la suya y la de su amante al seguir con su esposa (Gómez de Avellaneda, 1842-1843, II, p. 90), de modo que inevitablemente estaba destinado a hacer desgraciadas a ambas mujeres además de haber labrado su propia desdicha.

Tula no decantó sus preferencias por ninguna de sus protagonistas, igualmente nobles y generosas, aunque dedicó una atención más insistente a Catalina. La inocencia o simplicidad de Luisa resultaba menos interesante para ella y para sus posibles lectores que la complejidad de su rival, tan apasionada como infeliz, aspectos que la situaban por encima de la mediocridad ambiente. Ambas parecían coincidir en su afición por la lectura, quizá útil para precisar sus diferencias de carácter. Luisa, cándida y dulce, leía Pablo y Virginia en el momento decisivo de su reencuentro con Carlos - como los personajes imaginados por Bernardin de Saint Pierre, se habían criado como hermanos y estaban destinados al amor-, novela que como Robinson Crusoe de Daniel Defoe y Pamela o la virtud recompensada de Samuel Richardson podían conjugarse sin problemas con las lecturas propias de una formación religiosa y conservadora, que la preparaba para amar con pureza de ángel y abnegación de mujer. En profundo contraste, antes de vivir la pasión sublime que la llevaría a la infelicidad y a la muerte, la propia Catalina podía reconocer como un gran defecto que "su poderosa imaginación todo lo engrandecía o disminuía hasta el exceso; y las más extravagantes teorías se hacían realizables para aquella mujer capaz de los esfuerzos más sublimes, como de las aberraciones más lamentables, pero para la que no existía ningún término medio" (Gómez de Avellaneda, 18421843, III, pp. 16-17). Aunque dominaba el francés y sus conocimientos de inglés, alemán e italiano la habían permitido saborear todo lo interesante de las literaturas en esos idiomas, resulta significativo que entre sus lecturas solo se mencionasen con precisión dos novelas que en horas de tedio le proporcionara su difunto marido, aquel hombre maduro e incapaz de amar con el que se casara en plena juventud y que resultaba inadecuado para alguien como ella, plena de imaginación y sensibilidad: Julia, o La nueva Eloísa, de Rousseau, y Las desventuras del joven Werther, de Goethe, obras que de algún modo prefiguraban su destino. Rousseau reaparecía junto a Platón entre los filósofos en los que la condesa había buscado sentido 
para su vida ganándose a cambio la persecución de "los pálidos espectros de la duda" (Gómez de Avellaneda, 1842-1843, II, p. 106), sumiéndola en el desencanto y el escepticismo que solo por un tiempo las diversiones le permitieron soportar. Aunque al final Catalina rehuyera la literatura y en particular las novelas que mostraran alguna semejanza con su suerte, la escritora utilizó mucho de lo leído para imaginar a esa mujer culpable pero siempre noble y generosa hasta el punto de comprender los remordimientos de su amante y aun exigírselos, capaz de quitarse la vida para evitar el dolor y la muerte de su rival. Además, ese rechazo de las ficciones y de las teorías era parte de su encuentro con la realidad e incluso con la fe que podía dar sentido a su expiación del crimen cometido, y constituía un capítulo más en la serie de los que ya habían mostrado el abismo que mediaba entre la teoría y la práctica de las grandes pasiones, entre el amor alocado y sus consecuencias. Eran errores de la imaginación los que en buena medida habían determinado hasta entonces la infelicidad de Catalina, alimentando el choque entre los sueños y la realidad, entre el entusiasmo y los desengaños. No es infundado deducir que esos errores explicaban o justificaban después su desgracia, como si Gómez de Avellaneda anticipara como determinantes en el destino de su personaje algunos de los factores que Gustave Flaubert habría de imaginar cuando llevó a Emma Bovary al adulterio y al suicidio.

A estas alturas tal vez ya no vale la pena insistir en la espontaneidad de Tula a la hora de expresar sus sentimientos y de proyectarlos sobre sus creaciones literarias. Sin duda algo de sí misma puso en Catalina, cuando hizo que se la definiera por su carácter "independiente" y por sus opiniones "libres" (Gómez de Avellaneda, 1842-1843, I, p. 165), y que Carlos descubriera en ella a la mujer de talento y de corazón, conjunción extremada de pasión e inteligencia profundamente ligada a la desventura: un drama viviente, adornado de interminables atractivos físicos e intelectuales. No hacía otra cosa que proyectar en sus obras lo que en gran medida había requisado en la literatura para elaborar la imagen de sí misma que había construido, no por eso menos auténtica, y en todo caso determinante a la hora de elegir en adelante temas para sus ficciones. Puesto que se trataba de preferir el crimen a las bajezas y la mezquindad, el individuo a las convenciones sociales, no es de extrañar que Gómez de Avellaneda recreara en Espatolino, novela que el periódico literario madrileño El Laberinto dio a conocer en 1844, la historia del bandolero de ese nombre, célebre por sus fechorías en Nápoles y Roma durante la ocupación napoleónica de Italia, asignando a su personaje un destino romántico: perseguido por la adversidad que se cebaba en su familia, la deshonra lo llevaba al crimen, a la prisión y a la muerte. La autora no justificaba su conducta, pero trataba de despertar al menos la compasión del lector al encarecer la nobleza de sus sentimientos, su frustrada regeneración por el amor y la fatalidad que regía su existencia. Como en Dos mujeres, el final desgraciado ilustraría sobre las consecuencias nefastas de una conducta antisocial si la conducta de Espatolino no se presentara como el cumplimiento de un destino predeterminado e ineludible: sus inocentes amores con Luigia habían terminado cuando ella lo traicionó casándose con el infame Sarti, culpable de la ruina de su padre, y su hermana Giulietta había sido víctima de Carlos, el conde que parecía su mejor amigo y que la abandonó cuando su hermosura se marchitó tras hacerle padre de una criatura que vivió pocas horas. No era extraño que Espatolino intentase matar a este último y que eso le costara la cárcel, de donde salió como todo presidiario con "instintos de fiera" (Gómez de Avellaneda, 1870 , p. 280), lo que más que una condena - fugaz, por lo demás - del sistema penitenciario, era la explicación de la brutalidad inhumana que a veces demostró en su venganza. Quizá la autora encontrase grandeza y poesía en el crimen, al menos cuando se trataba de combatir la injusticia, pero lo comprobable es que colocó a sus personajes ante otra situación sin salida. El alma indómita del bandido, antes desconocedora del arrepentimiento, se transformó finalmente por amor a Anunziata, quien prefirió el amor al honor y la felicidad pero no dejó de marchitarse mientras compartía el destino de un réprobo, torturada por el recuerdo de los crímenes cometidos por su amante y empeñada en que este se reconciliara con Dios y con los hombres antes de que el patíbulo terminara con sus posibilidades de arrepentirse. Las circunstancias habrían de impedirlo precisamente cuando la espera de un hijo proyectaba sobre Espatolino alguna esperanza y voluntad de regeneración: el bandido murió sin confesión mientras Anunziata, a quien la locura hacía creerse reina, meditaba sobre "las ventajas e inconvenientes que ofrecía la abolición de la pena de muerte" (Gómez de Avellaneda, 1870, p. 363).

La simpatía que en la novela mostraban las mujeres por el bandido enamorado era sin duda la que Tula sentía, pues algo de positivo cabía descubrir en aquellos nómadas salvajes, feroces pero ajenos a la perfidia y falsedad de la civilización, mientras que la alevosía del agente de policía Angelo Rotoli, responsable último de la muerte de Espatolino, resultaba imperdona- 
ble. Se imponía el gusto romántico por los personajes marginales y los destinos adversos, que aves de mal agüero y fenómenos naturales vaticinaban. Además, los destinos del héroe y del bandido "filosóficamente no se diferencian mucho", como Tula habría de constatar a propósito de Hernán Cortés en Guatimozín, último emperador de México (Gómez de Avellaneda, 1846, I, p. 123), cuando, desposeída de sus justificaciones imperiales y religiosas de antaño, la actuación de los conquistadores en América tendía a convertirse en un acto de violencia y pillaje. Desde luego, esta vez las simpatías de Tula se inclinaban hacia el joven y heroico Guatimozín, símbolo del patriotismo, de la lucha de los pueblos por poder decidir su destino, otro tema grato al romanticismo, sin por ello apartarse de una visión de la conquista que la propia historiografía del momento, para la que resultó decisiva la contribución del hispanista norteamericano William $\mathrm{H}$. Prescott con su Historia de la conquista de México (1843), imponía al encontrar en la campaña de Cortés un episodio más novelesco que histórico, al considerar que aquel hecho de armas, "ejecutado por un puñado de aventureros, faltos de todo", era "un suceso casi milagroso que se desvía aun de las probabilidades que requiere la fábula, y que no admite paralelo en las páginas de la historia" (Prescott, 1843/1970, p. 521).

Si Guatimozín, último emperador de México fue resultado de una minuciosa investigación de documentos históricos relacionados con el tema novelesco abordado, lo que dejaba de manifiesto la condición libresca de la inspiración de la autora, justo es reconocer que ya Espatolino había manifestado la pretensión de reconstruir con precisión tiempos pasados, voluntad que alguna vez se conjugaba allí con el humor, como al comentar las fuentes de información que permitían obviar explicaciones sobre Italia o compartir con sus lectores la descripción de su geografía y el recuerdo de su historia antes de centrarse en el año 1811, cuando las tropas napoleónicas arrasaban aquellas tierras y se enfrentaban a la única resistencia de rebeldes vagabundos como ese famoso romano Espatolino, amante de la Virgen y autor de terribles hazañas. A ese respecto, por la voluntad de poner de manifiesto los artificios de la ficción que mostraron, merecen también atención las "leyendas" o "tradiciones" al gusto romántico que ya habían empezado a enriquecer la narrativa de Gómez de Avellaneda. Su variada extensión hace que a veces sean verdaderas novelas cortas, como es el caso de La baronesa de Joux, una "leyenda francesa" que Tula había encontrado en un poema de Auguste Demesmay -incluido en Traditions populaires du Franche-Comté. Poésies sui- vies de notes, editado en Besançon en 1838- y que El Globo dio a conocer en Madrid en 1844, ambientada en el siglo xII y en torno al majestuoso y sombrío castillo de Joux, en lo que hoy es el Franco Condado y entonces era condado de Borgoña, ligado al Sacro Imperio Romano-Germánico que gobernaba Conrado III y alterado por la segunda cruzada contra los turcos. La autora desarrolló allí la historia de amor a la que pusieron trágico fin la pasión y los celos de Amauri, barón de Joux, cuyo buen carácter desmentían anticipadamente rasgos que evidenciaban una índole rencorosa y tenaz así como poderosos instintos de orgullo y venganza - Tula se mostró con frecuencia interesada en la frenología a la hora de caracterizar a sus personajes-, y cuyas víctimas habrían de ser su esposa Berta de Luneville y el barón Aimer de Montfaucon, almas superiores y amantes ideales entre quienes se interpuso la fatalidad de un matrimonio impuesto por intereses económicos. La narradora proponía una idealidad tan poética como la que "realizaba" Berta a la vez que desdeñaba los logros de los modernos románticos, "apasionados por lo vaporoso y fantástico" (Gómez de Avellaneda, 1871, p. 195), con lo que demostraba conocer sus tópicos a la vez que los utilizaba y aun los exageraba al mostrar otro destino infausto, anticipado por presagios funestos y aderezado esta vez con una desbordada fantasía.

No es imposible ver en los tres últimos títulos mencionados la conformación de un nuevo ciclo en la narrativa de Gómez de Avellaneda, y al menos puede constatarse que esas ficciones recrearon tiempos pasados, lo que no solo permitía contraponer lo poético y lo prosaico en la historia narrada, sino también contrastar el pasado con el presente o realidad cotidiana de la autora y de los lectores. Resulta evidente, además, que la pretensión de mostrar caracteres verosímiles y pasiones naturales, declarada en Dos mujeres, iba relajándose a medida que la credibilidad de los hechos relatados pasaba a ser garantizada por documentos históricos o creaciones literarias previas, lo que los hacía interesantes no tanto por su verosimilitud como por su misma ambientación en tiempos remotos. Esa deriva habría de acentuarse en cuanto Tula decidió recurrir a fuentes orales que subrayaran en el relato su condición legendaria o de ficción, o, si se quiere, de mero pasatiempo. Fue lo que ocurrió con La velada del helecho o El donativo del diablo, que el Semanario Pintoresco publicó en 1849 , y en cuyas reflexiones introductorias la autora, en funciones de narradora, dejó claro no solo que recreaba una tradición suiza - la relativa a la supuesta aparición de Satanás a quienes velaran los helechos 
en la noche de san Juan, para ofrecerles riquezas a cambio de su alma-, sino el primitivo carácter oral de esa leyenda que ahora lamentaba presentar "con las comunes formas de la novela", consciente tanto del género literario al que recurría como de su incapacidad para reproducir la magia de simplicidad primitiva de "su relación verbal junto al fuego, en una fría y prolongada noche de diciembre" (Gómez de Avellaneda, 1871, p. 3). Había sentido esa magia al escuchar el relato de esos hechos, ambientados a principios del siglo $\mathrm{XV}$ en el cantón de Friburgo aún feudal, en boca de su hermano Manuel, quien había viajado por Europa durante un tiempo considerable. Ciertamente, los interesados en subrayar la faceta subversiva de Gómez de Avellaneda pueden recordar que encontró ocasión allí para hablar mal del fanatismo religioso, "creador del funesto tribunal que osó llamarse santo" (Gómez de Avellaneda, 1871, p. 46), pero la atención se centraba sobre todo en las intrigas que aderezaban otra historia de amor, con lo que la fascinación por la ficción en sí misma prevalecía sobre cualquier otra consideración. No en vano Tula había creído conveniente recordar allí al "célebre autor del Childe Harold" y exclamar con él: "iEsto es hermoso como la ilusión de un sueño!" (Gómez de Avellaneda, 1871, p. 29).

Para Dolores. Páginas de una crónica de familia, una leyenda o novela corta que el Semanario Pintoresco publicó en Madrid en 1851, Gómez de Avellaneda eligió un tema ambientado en la edad media española - los hechos narrados se iniciaban en Valladolid en la fecha precisa del 12 de enero de 1425 - y personajes que otra vez eran víctimas de sus sentimientos exaltados y de sus pasiones incontrolables: allí era un puntilloso concepto del honor lo que llevaba a doña Beatriz de Avellaneda -esposa de Diego Gómez de Sandoval, conde de CastroXeriz - a oponerse a la boda de su hija Dolores con Rodrigo de Luna, un bastardo que era sobrino del también bastardo don Álvaro de Luna, dispuesta por el rey Juan II de Castilla, sabedor del amor que ligaba a los dos jóvenes. Los prejuicios contra quienes "debían la existencia a mujeres de ínfima clase y de no honesta nombradía" (Gómez de Avellaneda, 1870, p. 389) eran esta vez el motivo último que desencadenaba la infelicidad general, paliada el final por los buenos sentimientos de Dolores, quien, a sabiendas de que Rodrigo ya era "ministro del Señor", decidía retirarse a un convento para allí poder tributar a Jesucristo su agradecimiento "por haber purificado - con el fuego eterno de su amor divino- dos juveniles corazones que habían cifrado su dicha en las pasajeras satisfacciones de una pasión terrestre" (Gómez de Avellaneda, 1870, p. 432). No podía faltar la mención de Walter Scott, "el más inteligente, el más profundo, el más brillante y elocuente pintor de los tiempos caballerescos", esta vez para excusar la descripción de las justas celebradas en ocasión del bautismo del augusto heredero de reino de Castilla, no porque Gómez de Avellaneda se creyera incapaz de lucir sus profundos conocimientos sobre el tema, sino para evitar contarse entre "tantos copiantes de brocha gorda" como imitaban al famoso novelista escocés (Gómez de Avellaneda, 1870, p. 386). Esas razones la libraban de incurrir en la inoportuna e impertinente pretensión de entretener al público "positivista y bursátil" de una época incapaz de apreciar los buenos golpes de lanza y la galantería de los amores platónicos - no olvidaba el conflicto entre lo sublime y lo pedestre que la obsesionaba-, lo que no le impedía narrar sucesos acontecidos en un pasado remoto, sin que ello equivaliera a añorar otros tiempos y lamentar los presentes, pues se declaraba convencida de que cada época tenía sus excesos y sus extravagancias peculiares en los que radicaba lo mejor y más poético que podían ofrecer.

Tula dejaba para otra ocasión lo que tuvieran de grandioso tanto "las buenas edades de los mandobles" como las no menos afortunadas de "las operaciones de bolsa y los corsés sin costuras" (Gómez de Avellaneda, 1870, p. 387), y en Dolores se centró en el desarrollo de otra historia de pasiones contrariadas que esa vez se resolvían en la paz de un amor místico. Puesto que ya no se trataba tanto de contraponer el pasado a la actualidad como de contrastar en cada época la vulgaridad cotidiana con los aspectos peregrinos que pudieran servir de inspiración al escritor, la literatura bien podía verse como el espacio autónomo donde se concretaban los valores poéticos propios de la ficción, incluida la justicia "poética". Es lo que cabe deducir de La montaña maldita, "tradición suiza" que había llegado hasta Gómez de Avellaneda por medio de su hermano Manuel y que el Semanario Pintoresco publicó también en 1851: era la historia de la pobre Marta y de su único y rico hijo Walter Muller, cuya conducta desnaturalizada con su madre - por su nacimiento oprobioso, motivo significativamente reiterado en estas ficciones $-\mathrm{y}$ con su hermosa ternera blanca determinaba la maldición de la anciana y con ello el castigo en forma de derrumbamiento que bajo espesas capas de hielo y piedras dejó para siempre enterrados a hombres, ganados y casas de la que había sido hasta entonces la montaña florida, la famosa Blumlisalp. 
Resulta difícil precisar si el pensamiento de Tula y su visión de sí misma habían evolucionado acordes con el proceso que su narrativa parecía seguir. Sus cartas a Antonio Romero Ortiz, con quien mantuvo un romance en 1853, confirman su convicción de vivir "en un siglo de prosa y de positivismo" (Gómez de Avellaneda, 1975, p. 12), lo que no era una novedad, como tampoco lo era que resaltase lo extemporáneo de su condición de poeta y de las inquietudes espiritualistas que eso conllevaba, inquietudes que no bastaban para sacarla del tedio infecundo en el que se decía sumida. Esas cartas también permiten deducir que lo egoísta y falso resultaba incompatible con lo que podía suscitar su amor por alguien, y constatar que le parecía imposible "el vivir sin amar y el amar sin morir" (Gómez de Avellaneda, 1975, p. 27), lo que condecía con los personajes que iba forjando su imaginación: no en vano se consideraba "capaz de amar a un pirata, a un bandido, a un fraile", si alguno de ellos se mostrara capaz ofrecerle un amor tal como ella lo concebía, mientras la ilusión que pudiera inspirarle "el hombre más lleno de mérito y de gloria y de poder" se desvanecería "desde el momento en que viese en él falsedad y egoísmo y artificio mezquino" (Gómez de Avellaneda, 1975, p. 23). Tales declaraciones no impiden comprobar que Tula veía en la libertad individual una quimera, puesto que viuda, independiente de carácter y con disposición plena para hacer su voluntad, se asignaba los deberes de evitar sufrimientos a su madre y de respetar por siempre el nombre de su esposo difunto, lo que parecía condenarla a vivir en la clandestinidad su nuevo amor, que además debía ser puro para hacerla feliz y se volvía vulgar y vergonzoso en cuanto le hacía "desear delicias terrenales" (Gómez de Avellaneda, 1975, p. 43). No faltan razones para deducir que, al buscar inspiración en la historia y las leyendas, trataba de alejarse de la degradación prosaica de su propia vida cotidiana, a la que la poesía de sus ficciones servía de compensación o contrapunto. Probablemente ya nunca abandonó ese territorio paralelo, cualesquiera que fuesen las circunstancias que en adelante condicionaron su vida y su obra.

Durante los viajes a los Pirineos que realizó con Domingo Verdugo y Massieu en los veranos de 1858 y 1859, Tula encontró los temas de La bella Toda y Los doce jabalíes ("dos tradiciones de la Plaza del Mercado de Bilbao"), La dama de Amboto ("tradición vasca") y La flor del ángel ("tradición vascongada"), así como el de La ondina del lago azul. Ella misma asoció con su estancia en Bilbao en 1858 las dos primeras "tradiciones", relatos de dramáticos hechos ocurridos siglos antes y relacionados entre sí por haber acon- tecido parcialmente en la antigua Plaza Mayor de la ciudad vizcaína. También recreó pasiones y crímenes lejanos La dama de Amboto, donde se han encontrado propósitos de denuncia social contra los privilegios del varón y una intención aún menos comprobable de subvertir los paradigmas de la mujer impuestos por la cultura patriarcal dominante (Selimov, 2003, pp. 7579). Sin embargo, puesto que la hermosa protagonista de este relato no sufrió los rigores extremos a que se veían condenadas otras mujeres de su época, conviene reparar en que alguna vez lo febril de su mirada y lo siniestro de su expresión dejaron entrever la relación de su carácter esquivo y huraño con el odio y los ensueños delirantes que la llevarían a asesinar a su cariñoso hermano, crimen que hubo de pagar con los remordimientos que la condujeron a la locura y a la muerte: expiación insuficiente a juzgar por la condición errante de esa alma que abandonaba su tumba para anunciar desgracias. En suma, se trataba ante todo de una historia fascinante de pasiones tan intensas como oscuras y terribles, no menos atractivas para la autora que la relatada en La flor del ángel, donde en notorio contraste recogía una leyenda de amor contrariado y sin embargo constante hasta la muerte y más allá -Juan Eugenio Hartzenbusch había recreado una leyenda semejante en Los amantes de Teruel, drama del que Tula recordó algunos versos-, pasión que permitía explicar el origen de la peculiar orquídea conocida como "flor de la abeja". Y antes de concluir su temporada veraniega de 1859, durante una excursión al lago Azul realizada desde la localidad francesa de Bagnères-de-Bigorre, Gómez de Avellaneda escuchó la leyenda recreada en La ondina del lago azul, protagonizada por el bello y melancólico Gabriel, a quien sus libros y la música de su flauta ya mantenían ajeno a todo interés material y social cuando, inmerso en un mundo de ensueño y ajeno al "frío positivismo" (Gómez de Avellaneda, 1871, p. 123) que consideraba incompatible con su alma, el amor por una ondina lo llevaba a morir en el lago. Sobre esa historia de amor desdichado se proyectaba al final la sospecha de que el joven había sido víctima de una farsa, de que su suerte había sido el "horrible efecto de la burla lanzada por la prosaica realidad sobre la poética aspiración" (Gómez de Avellaneda, 1871, p. 145). El conflicto entre las ilusiones y la realidad volvía a merecer la atención de la escritora, que no perdía la ocasión para poner de manifiesto una vez más la condición literaria de ese conflicto: no en vano su informante accedía a referir la leyenda por considerar a Tula "afecta a todo lo maravilloso" (Gómez de Avellaneda, 1871, p. $117)$, mientras sus virtudes como narrador traían a la 
memoria de ella la habilidad con que los folletinistas franceses Alexandre Dumas (padre) y Frédéric Soulié sabían captar la atención para sus historias.

Su traslado a Cuba en el otoño de 1859 no alteró el interés de Gómez de Avellaneda por las leyendas. En 1860 publicó allí La dama de Amboto, La flor del ángel y La montaña maldita en su Álbum Cubano de lo Bueno y lo Bello, y en el Diario de la Marina, incluidas en "Mi último viaje a los Pirineos", La bella Toda, Los doce jabalíes y La ondina del lago azul. Allí escribió El aura blanca, donde recogió una tradición o recuerdo de un extraño suceso ocurrido años atrás en Puerto Príncipe, su ciudad natal, protagonizado por un franciscano conocido como padre Valencia, quien en vida se había distinguido por su bondad y en particular por sus esfuerzos en favor de los leprosos de Camagüey, y que tras su muerte se había transformado en un aura o gran buitre cubano, cuyo extraño color blanco atrajo la curiosidad y los recursos suficientes para sostener el hospital de San Lázaro que él mismo había fundado. El regreso a su tierra fue también un estímulo para que Tula redactara El cacique de Turmequé, "leyenda americana" que encontró su inspiración en los capítulos XIII y XIV de Conquista y descubrimiento del Nuevo Reino de Granada de las Indias Occidentales del Mar Océano, y fundación de la ciudad de Santa Fe de Bogotá, de Juan Rodríguez Freyle (Fresle según la primera edición, publicada en 1859 en Bogotá por la Imprenta de Pizano y Pérez). Desde 1579 , con la llegada del visitador Juan Bautista Monzón, hasta 1582, cuando entró en escena Juan Prieto de Orellana como nuevo visitador, graves desórdenes alteraron la vida de Santa Fe de Bogotá a causa del enfrentamiento de Monzón con Lope Díez de Armendáriz y sus partidarios, conflicto enriquecido con intrigas amorosas que daban pie para que Tula volviese sobre planteamientos que habían sido bien suyos: no en vano la hermosa Estrella se aburría tras dos años de casada "porque su novelesca imaginación no hallaba el idilio que había soñado en la historia real del matrimonio; y una serie de falsos raciocinios la había casi convencido de que debía ser desgraciada" (Gómez de Avellaneda, 1871, p. 233). Era la imaginación propia de alguien cuyos libros predilectos "eran todos de aventuras de caballería y de amorosas intrigas" (Gómez de Avellaneda, 1871, p. 239) y que buscaba constantemente nuevas impresiones. La consecuencia fue su adulterio con el fiscal Antonio de Orozco, adúltero a su vez, y luego su pasión por don Diego de Torres, cacique de Turmequé, cuya figura Gómez de Avellaneda aderezó con "la singular belleza producida comúnmente por el cruzamiento de razas"
(Gómez de Avellaneda, 1871, p. 235). La ocasión era propicia para acordarse de Alejandro Dumas (padre) a propósito de Juan Roldán, el Artagnan de Bogotá, quien no fue capaz de convencer al cacique para que huyese de quienes conspiraban contra él, pero consiguió salvarlo de la muerte a la que estaba destinado. Por cierto, Tula hizo constar allí que se la acusaba "de tendencias grandes hacia lo trágico" y reconoció que gustaba de hacer patente en sus obras "la ineludible ley de las expiaciones" (Gómez de Avellaneda, 1871, p. 275). Por si los relatos anteriores no habían demostrado suficientemente esa última inclinación, El cacique de Turmequé ofrecía una prueba más al entender como expiación el trabajo final del mestizo, empleado en la caballeriza del rey Felipe II, así como al castigar a Orozco con la locura. Rodríguez Freyle no supo jamás de esta condena, ni había considerado infausto el destino asignado a don Diego de Torres.

Como El aura blanca y El cacique de Turmequé, en el quinto y último volumen de las Obras literarias de la señora doña Gertrudis de Avellaneda se publicó por primera vez, en 1871, Una anécdota en la vida de Cortés. En nota a pie de página se aseguraba que "esta anécdota, tomada de su novela Guatimozín, es lo único que la autora ha querido conservar de dicha obra, suprimida en la presente colección a causa de no haberle permitido su falta de salud revisarla y corregirla, según juzga necesario" (Gómez de Avellaneda, 1871, p. 159). No era otra cosa que el epílogo de la novela modificado en la medida necesaria para ofrecer una imagen menos negativa del conquistador, aunque no se olvidase la crueldad inútil e indigna con que trató a su prisionero Guatimozín, torturado para que revelara el lugar en que habría ocultado supuestos tesoros y condenado a morir en la horca por participar en una conjuración de la que no había prueba alguna. Tales deméritos, interpretados como concesiones al espíritu bárbaro de una época sangrienta, no bastaban para eclipsar la superioridad de Hernán Cortés, aquel genio de la milicia siempre en lucha con la vulgaridad hostil de la inmensa mayoría, expuesto a los embates de la envidia, la calumnia y la deslealtad, y además pasaban a un segundo plano desplazados por la apasionada Marina, que impulsada por el amor y los celos asesinaba a la viuda del último emperador mexicano, acrecentando de paso los muchos sufrimientos que el héroe afrontaba por plantar la cruz de la civilización cristiana en el Nuevo Mundo.

Tula parecía así seguir fiel a su interés por los grandes criminales y las pasiones intensas, aunque había dado a estas últimas una nueva orientación en su novela $E I$ 
artista barquero o los cuatro 5 de junio, que la Librería e Imprenta El Iris publicó en La Habana en 1861. Recuperó allí algunos episodios al parecer inspirados en la vida del pintor francés Hubert Robert, quien se enamoró de la bella cubana Josefina Caillard cuando en Marsella afrontaba la extrema pobreza que le impedía cultivar su vocación artística, se mantuvo fiel mientras triunfaba en París bajo la protección de Juana Antonieta Poisson, Marquesa de Pompadour, y terminó uniéndose a ella en un matrimonio que después de varios años aún llegaba feliz al final del relato. A la vez que aprovechaba la ocasión para exaltar la naturaleza de su isla natal, para recrear las fiestas, intrigas y placeres de la corte de Versalles y para mostrar sus convicciones sobre la condición del arte y del artista, la autora ponía al pintor en un dilema similar al afrontado por Carlos en Dos mujeres, aunque ahora, por suerte para Huberto y para Josefina, el conflicto se resolvía antes de la boda a costa de la célebre favorita de Luis XV, que hasta entonces no había conseguido vivir un amor verdadero - no lo era el que la unía al rey, en cuyos brazos la había arrojado el aburrimiento de su matrimonio-, y tampoco habría de vivirlo con aquel joven pintor que con un boceto había despertado su melancolía y el deseo de conocerlo, para luego convertirse en su protectora y enamorarse de él. El rechazo sufrido constituía la expiación de Madame Pompadour, quien no pudo purificarse con una pasión auténtica pero lo consiguió aceptando su sacrificio con magnánima actitud: otra vez la mujer impura demostraba en la renuncia toda su grandeza, que la llevaba incluso a actuar como madrina de boda de su feliz rival.

La pureza del protagonista había resistido esta vez todas las tentaciones, para lo que en todo momento había contado con el apoyo poderoso e incondicional de la Providencia. La personificaba un benefactor desconocido - Huberto y los lectores descubrían al final que se trataba de Carlos Luis de Secondat, barón de Montesquieu, fallecido el 10 de febrero de 1755, día de la boda-, quien, recordando lo que ya había dicho al joven pintor en su primer encuentro, le insistía por carta en que "la Providencia no desampara a los buenos" (Gómez de Avellaneda, 1870, p. 63), a la vez que lo ayudaba con su dinero, sus consejos y su influencia a seguir la senda de la virtud y a alcanzar el éxito y la felicidad. Ese providencialismo ofrecía otras muchas manifestaciones, lo mismo al corregir con los celos la aspiración de los amantes a hacerse un cielo en la tierra que al resolver situaciones complicadas con oportunas enfermedades pasajeras. Por esa vía parecía anularse en alguna medida el conflicto entre el idealismo y la realidad, a la vez que la inocencia original triunfaba sobre la vulgaridad positivista, las miserias de la condición humana, la prosa de la vida. Tal planteamiento puede entenderse como consecuencia de la proyección de convicciones religiosas sobre la elaboración de la trama novelesca, pues no en vano Gómez de Avellaneda había apostado por acercar la función del artista a la del Creador cuando presentaba su Álbum Cubano de lo Bueno y lo Bello. Lo cierto es que Tula había encontrado otra forma de causalidad legítima para la ficción, en una prueba más de la consciencia con la que dominaba el arte de narrar: una habilidad al servicio de la imaginación, que en su caso siempre se había nutrido de literatura, de esa misma literatura que la había ayudado a elaborar sus sentimientos y a construir la imagen de sí misma que proyectó en su vida y en su obra.

\section{NOTAS}

1 Como Sab y Dos mujeres, Guatimozín, último emperador de México fue recuperada en la Edición Nacional de las Obras de Gertrudis Gómez de Avellaneda (1914), realizada con motivo del centenario de su nacimiento.

\section{BIBLIOGRAFÍA}

Castillo de González, A. (1887). Biografía de Gertrudis Gómez de Avellaneda y juicio crítico de sus obras. La Habana: Imprenta de Soler, Álvarez y Cía.

Gómez de Avellaneda, G. (1841). Sab. Madrid: Imprenta Calle del Barco núm. 26.
2 Cabe pensar, con Carmen Bravo-Villasante, que "el tema de la esclavitud era tan peligroso en la España de 1865 que una novela que manifestase un partidismo declarado podía perjudicar a la misma autora, que, hasta cierto punto, gozaba del favor de la corte" (Gómez de Avellaneda, 1970, p. 22), y que, al abordar temas relacionados con la conquista de América, Tula, "que vivía en España, donde había triunfado, y que se consideraba tan española como cubana, tenía que medir sus palabras en cuestiones tan graves para su patria adoptiva" (Gómez de Avellaneda, 1970, p. 29).
Gómez de Avellaneda, G. (1842-1843). Dos mujeres. Madrid: Gabinete Literario.

Gómez de Avellaneda, G. (1846). Guatimozín, último emperador de Méjico. Madrid: Imprenta de D. A. Espinosa y Compañía.
Gómez de Avellaneda, G. (1870). Obras literarias de la señora doña Gertrudis de Avellaneda (tomo IV. Novelas y Leyendas). Madrid: Imprenta y Estereotipia de M. Rivadeneyra.

Gómez de Avellaneda, G. (1871). Obras literarias de la señora doña Gertrudis de Avellaneda (tomo V. Novelas y leyen- 
das). Madrid: Imprenta y Estereotipia de M. Rivadeneyra.

Gómez de Avellaneda, G. (1914). Autobiografía y cartas (hasta ahora inéditas) de la ilustre poetisa Gertrudis Gómez de Avellaneda, con un prólogo y una necrología de L. Cruz de Fuentes (segunda edición, corregida y aumentada). Madrid: Imprenta Helénica, 1914.
Gómez de Avellaneda, G. (1970). Sab. Salamanca: Ediciones Anaya.

Gómez de Avellaneda, G. (1975). Cartas inéditas existentes en el Museo del Ejército. Madrid: Fundación Universitaria Española.

Prescott, W. H (1843/1970). Historia de la conquista de México. México: Porrúa.
Selimov, A. R. (2003). De la ilustración al modernismo: la poética de la cultura romántica en el discurso de Gertrudis Gómez de Avellaneda. Boulder, Colorado: Society of Spanish and Spanish-American Studies, University of Colorado. 